Escritos / Medellín-Colombia / Vol. 25, N. 54 / pp. 221-240 Enero-junio, 2017 / ISSN 0120-1263 / ISSN: 2390-0032 (en línea)

http://dx.doi.org/10.18566/escr.v25n54.a10

\title{
LA NUEVA BALSA DE LA MEDUSA: LOS EMBRIONES SOBRANTES. OBSERVACIONES SOBRE LA DESHUMANIZACIÓN EN UN ASPECTO DE LAS APLICACIONES DE LA TECNO-CIENCIA CONTEMPORÁNEA
}

\author{
THE NEW RAFT OF THE MEDUSA: \\ THE REMAINING EMBRYOS. ON THE \\ DEHUIMANIZATION IN ONE PARTICULAR ASPECT \\ OF THE APPLICATION OF CONTEMPORARY \\ TECHNOSCIENCE
}

\section{A NOVA BALSA DE MEDUSA: OS EMBRIÕES SOBRANTES. OBSERVAÇÕES SOBRE A DESUMANIZAÇÃO EM UM ASPECTO DAS APLICAÇÕES DA TECNOCIÊNCIA CONTEMPORÂNEA}

Carlos Alberto Gómez Fajardo*

* MD Ginecólogo-Obstetra de la Universidad Pontificia Bolivariana. Especialista en Bioética de la Universidad de la Sabana. Docente Instituto de Humanismo Cristiano, área de Bioética. Universidad Pontificia Bolivariana, Medellín, Colombia.

Correo electrónico: cgomezfaj@gmail.com

Artículo recibido el 30 de marzo de 2016 y aprobado para su publicación el 30 de septiembre de 2016. 


\section{RESUMEN}

El presente artículo busca presentar consideraciones bioéticas y antropológicas relacionadas con el documentado hecho de la alta pérdida de embriones que ocurre con la aplicación de las tecnologías de reproducción asistida en humanos. Se ilustran datos numéricos disponibles, provenientes del "2013 Assisted Reproductive Technology. National Summary Report" del CDC. Dada la alta pérdida de vidas humanas en estos procesos y los factores de insolidaridad y de ocultamiento del respeto por el derecho a la vida humana sin excepción, se plantea la existencia de una similitud con la trágica situación de los náufragos de la Medusa, clásica obra de Géricault, en los inicios del siglo XIX. Se intenta, además, desde la disciplina de la bioética, llamar la atención sobre la necesidad de una formación de la conciencia crítica en este tema, pues no todo lo factible técnicamente tiene licitud ética a la luz de la razón.

\section{PALABRAS CLAVE}

Tecnologías de Reproducción Asistida en Humanos, Tecno-ciencia, Deshumanización, Bioética, Conciencia.

\section{ABSTRACT}

The article aims to present bioethical and anthropological considerations regarding the documented fact of the high loss of embryos during Assisted Reproductive Technologies (ART) treatments for humans. Quantitative data available in the "2013 Assisted Reproductive Technology. National Summary Report" by the CDC is presented and illustrated. Considering the high loss of human lives during the cycles, the lack of solidarity, and the concealment of respect for the right to life, it is proposed that there is a similarity with the tragic situation of the shipwrecked persons of the Méduse at the beginning of the $19^{\text {th }}$ century -depicted in one of Géricault's paintings. From the standpoint of Bioethics, the article also seeks to raise awareness about this issue, because not everything that is technically possible is ethically lawful in light of reason.

\section{KEY WORDS}

Assisted Reproductive Technologies (ART), Technoscience, Dehumanization, Bioethics, Awareness.

\section{RESUIMO}

O presente artigo procura apresentar considerações bioéticas e antropológicas relacionadas com o fato documentado da alta perda de embrióes que ocorre na aplicação das tecnologias de reprodução assistida em humanos. Ilustram-se dados numéricos disponíveis, tomados do "2013 Assisted Reproductive Technology. National Summary Report" do CDC. Devido à alta perda de vidas humanas nesses processos e aos fatores de falta de solidariedade e de ocultamento do respeito pelo direito à vida humana sem exceção, propõe-se a existência de uma semelhança, com a trágica situação dos náufragos da Medusa, obra clássica de Géricault, nos inícios do século XIX. Tenta-se, além disso, chamar a atenção, desde a disciplina da bioética, sobre a necessidade de uma formação da consciência crítica sobre esse tema, posto que não tudo o factível tecnicamente tem legitimidade ética à luz da razão.

\section{PALAVRAS-CHAVE}

Tecnologias de Reprodução Assistida em Humanos, Tecnociência, Desumanização, Bioética, Consciência. 


\section{Introducción}

"Toda técnica es ambivalente, todo instrumento es ontológicamente ambiguo. Puede ser empleada para bien o para mal. Cuanto más decididamente ocupa la técnica el centro de interés de la actuación médica, tanto mayor es el peligro de que se oculte lo humano en el médico y el paciente". Alfons Auer.

"La barbarie del 'especialismo', cima de la humanidad europea". José Ortega y Gasset.

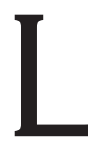

as Tecnologías de Reproducción Asistida aplicadas en seres humanos son presentadas como una victoriosa adquisición de una versátil capacidad del poder hacer tecno-científico, algo muy coherente con el espíritu utilitario y pragmático del siglo XX. En diversos campos del quehacer humano los hitos superados son dramáticos y rápidos. En el curso de pocas décadas se pasó por hechos como el descubrimiento de la estructura helicoidal del DNA por Watson y Crick, el uso de la energía atómica con fines bélicos o de generación de energía, las históricas conquistas de metas en la competencia aeroespacial, la masificación del uso de las tecnologías de información y telecomunicaciones. En este mundo occidental desarrollado, las sociedades del bienestar han obtenido unos logros sociales que a principios del siglo XX serían difíciles de imaginar y que se traducen en los avances de índices de desarrollo humano que tratan de aproximarse objetivamente a la cuantificación de este progreso.

En sus inicios, las intervenciones sobre aspectos de la vida naciente en mamíferos parecían destinadas al ámbito de la productividad industrial de la zootecnia y medicina veterinaria, aunque desde los años treinta del pasado siglo ya algunas voces como la de Aldous Huxley, que en su novela Un mundo feliz (1932) relata la práctica de una sociedad de clases seleccionadas genéticamente, imaginaban, de modo premonitorio, unos escenarios de innovación asombrosos en lo que atañe a los aspectos del control de la sociedad, el dirigismo de las masas y la modificación de los modos de reproducción en la especie humana. En fecha cercana, el español José Ortega y Gasset reflexionaba sobre fenómenos de gran envergadura social en La rebelión de las masas, donde cuestionaba 
la deshumanización de Europa y hacía referencia a los tecnócratas, especializados cada vez en áreas más limitadas del saber, que perdían fácilmente de vista el alcance y el horizonte humano de sus acciones (1).

Los avances en reproducción humana fueron posibles por una suma de adquisiciones en diversos campos del conocimiento: morfología, embriología, fisiología y endocrinología del ciclo reproductivo de los mamíferos, bioquímica de los esteroides sexuales, síntesis y uso clínico de hormonas con poderosos efectos sobre la ovulación, capacidad de control y seguimiento de los fenómenos de ovulación, captación laparoscópica de oocitos humanos, manipulación de estos en condiciones de laboratorio, técnicas de crio-preservación de tejidos, de gametos y embriones en diversos momentos del desarrollo, tecnología de ultrasonido para el monitoreo y captación del crecimiento folicular, uso de úteros subrogados, métodos genéticos de diagnóstico pre-implantatorio, sistemas de calificación de calidad embrionaria de acuerdo a criterios morfológicos o genéticos (2). Es tan grande y complejo el conocimiento técnico y sus aplicaciones en diversos campos, que se ha llegado al extremo de un grado de desinterés o de saturación de la opinión pública en lo que atañe a los logros y aplicaciones de las diversas técnicas relacionadas.

Se suele hacer referencia a todo lo anterior como avance simplemente, evadiendo el fondo antropológico racional de lo que constituye un hecho cierto y cabalmente documentado: los embriones humanos "sobrantes", producto del uso de estas aplicaciones, se cuentan por miles, por millones; y de modo práctico, sistemático y deliberado, se pierden y se eliminan en los procesos involucrados. Se oculta o se le resta importancia a este hecho, que pareciera tener escasa pertinencia. Que se trate precisamente de embriones humanos no es algo que suscite reacciones de carácter público.

Por décadas, las observaciones sobre este pavoroso escenario de pérdida de vidas humanas en manos de quienes la manipulan, han pertenecido a reducidos ámbitos académicos, sin la resonancia que debieran tener. En este mismo escenario, el activismo por los derechos humanos impregna prácticamente todos los sectores de la sociedad como algo que sucede de modo simultáneo a la pérdida del interés general que parece suscitar 
el hecho de los embriones perdidos o desechados. Esto corresponde a un actual panorama en el que priman el cinismo y la indiferencia selectiva ante el hecho de la pérdida de lo humano en el horizonte de la vida cotidiana, tal como algunos autores lo han señalado desde hace décadas. No puede ser moralmente neutro el significado de estos sucesos.

\section{Una metáfora: la balsa de La Medusa}

La tragedia de los embriones aniquilados durante las aplicaciones de las diversas Tecnologías de Reproducción Asistida hoy podría asimilarse a la de las víctimas del dramático naufragio de la fragata francesa La Medusa en 1816 frente a la costa de África Occidental, inmortalizado en la obra de 1819 del pintor romántico Théodore Géricault. La sociedad de la época se conmovió ante el drama de aquellos abandonados por la ineptitud del capitán de la nave, cuyos errores la condujeron al desastre. Unos náufragos, confinados a una precaria balsa, sin agua dulce ni provisiones, vivieron una pesadilla que muy pocos sortearon con vida. Se dieron casos de asesinatos, de canibalismo, de lucha sin piedad por las mejores posiciones en el frágil medio de salvación. Los hechos, sabidos por la opinión pública, fueron inspiración para la dramática obra que se conserva en el museo del Louvre; es universalmente conocida y representa a aquellos seres humanos en máxima condición de olvido y desesperación. En ese sentido, puede afirmarse que los miles de embriones humanos sobrantes de las técnicas de reproducción asistida equivalen a aquellos desesperados náufragos cuya historia fue dada a conocer en su momento y llevó a algunos a tomar mayor conciencia sobre las circunstancias en que perecieron.

El doloroso símil podría tener aplicación contemporánea entendiendo que los aportes y objetivos de la disciplina de la bioética, como lo propone A. Pessina, incluyen la formación de la conciencia crítica en la civilización tecnológica. Cuando por todos los medios se reafirman los derechos humanos, se moviliza a la opinión pública global en el sentido de generar solidaridad para con los inmigrantes, que por los cuatro puntos cardinales del mundo tratan por todas las maneras de hallar un futuro mejor, huyendo desesperadamente de sus naciones asoladas por la violencia, la ausencia 
de oportunidades laborales y el desamparo económico, se guarda silencio sobre los embriones sobrantes -seres humanos concebidos in vitromanipulados comercialmente, y de modo masivo llevados a un destino quizás peor que el de los inmigrantes que desaparecen en costas y mares: la muerte casi segura. A ello apuntan estas observaciones.

\section{Breve nota histórica}

El conocimiento descriptivo y la capacidad de manipulación tecnológica de los fenómenos reproductivos de los mamíferos son resultantes de una larga tradición de avances en diversas áreas. De modo esquemático, no exhaustivo, podrían destacarse algunos momentos que constituyen mojones de referencia para la comprensión actual de lo que ha sido esta escena de adquisiciones de conocimientos del proceso reproductivo. Se incluyen aquí la comprensión de la esteroidogénesis ovárica, el entendimiento de la anatomía y fisiología del eje neuro-endocrino hipotálamo-hipófisis-ovario, la capacidad de inducción farmacológica de la ovulación y su seguimiento por ultrasonido.

A ello se añaden lo que ya son rutinarias aplicaciones masivas en medicina veterinaria y zootecnia en reproducción de bovinos y otras especies, los avances quirúrgicos como laparoscopia, y por supuesto, el progresivo poder técnico del desarrollo de medios de cultivos celulares, métodos de crio-preservación de gametos, tecnología genética para detección e identificación de información del ADN -tecnologías PCR y FISH-, micromanipulación de gametos y embriones, sistemas de valoración de "calidad embrionaria" usados sistemáticamente en la selección de los mismos. Pueden señalarse algunos momentos de interés como destacados en la evolución histórica de las tecnologías de reproducción asistida y hechos conexos como (3):

1913 Albert Branchet: cultivo in vitro de embriones pre-implantatorios.

1932 Publicación de la novela Un mundo feliz, de Aldous Huxley.

1936 Gregory Pincus: Monografía The eggs of mammals -que incluye un capítulo sobre el cultivo de embriones en estados iniciales de desarrollo-. 
1948 Menkin; Rock: Fertilización in Vitro con gametos humanos

1956 Descripciones del desarrollo embrionario humano -Harvard Medical School: A. Hertig, J. Rock, E. Adams-.

1956 M. Chang: Fertilización In Vitro en conejos

1961 Klein y Palmer: Recuperación laparoscópica de oocitos humanos

1973 Criopreservación; selección de sexo en bovinos con tecnología PCR.

1978 Nacimiento de Louise Brown, primera "bebé probeta". -Birth after the reimplantation of human embryo. Lancet1978 2:366 PC Steptoe RG Edwards-.

1980 Lopata. Uso del citrato de Clomifeno en inducción de la ovulación.

1983 Mejoramiento de los protocolos de inducción de ovulación mediante uso de la combinación de Citrato de Clomifeno y hormonas hipofisiarias (HMG, GnRH, FSH).

1984 Warnock Report of the Committee of Inquiry into Human Fertilisation and Embriology.

1987 Donum Vitae: Instrucción sobre el respeto de la vida humana naciente y la dignidad de la procreación. Congregación para la Doctrina de la Fe.

1987 Concepto MOET en tecnologías de reproducción asistida en bovinos -MOET: multiple ovulation and embryo transfer-.1996 Clonación de la oveja Dolly -lan Wilmut-.

2010 Consenso de Estambul sobre evaluación de calidad embrionaria -ESHRE Human Reproduction vol. 26 N. 6 (2011): 1270-1283. The Istambul consensus workshop on embryo assessment: proceeding of an expert meeting-.

\section{La norma jurídica: arbitrariedad y utilitarismo}

Tiene gran importancia histórica el reporte de la "Comisión Warnock" en 1984. Como fruto del concepto de aquella comisión ante las autoridades sanitarias del Reino Unido se dio luz verde al uso de embriones menores de determinada edad gestacional -14 días- con la argumentación de que el embrión humano no puede ser considerado persona -y con ello sujeto de derechos humanos-, sino que es simplemente un aglomerado de células. Esta idea, acogida por la HFEA -Human Fertilisation and Embriology 
Authority- de ese país, también dio vía libre a que posteriores legislaciones de otras naciones europeas fueran igualmente permisivas con el uso de embriones de menores de dos semanas para diferentes aplicaciones.

Son interesantes, no obstante, algunas de las voces que en el interior de la misma comisión expusieron las razones de su disenso respecto a las recomendaciones mayoritariamente aceptadas. De modo contundente y documentado, serios investigadores de diversas disciplinas y orígenes han desenmascarado la evidente contradicción en que incurrió la citada comisión Warnock. Mediante una artificiosa manipulación lingüística se obviaron las evidencias que se conocen sobre el desarrollo embrionario precoz y se dio licencia a que las autoridades de salud de Gran Bretaña concediesen las bases para una licitud jurídica de las aplicaciones prácticas de las tecnologías de reproducción en seres humanos. Así se permitió la extensiva conducta de la manipulación de embriones menores de 14 días de edad, momento del desarrollo embrionario correspondiente a la diferenciación y cierre de la cresta neural.

Aquel erróneo y arbitrario concepto, fijando el límite de los 14 días como hito cronológico hasta el cual se autoriza jurídicamente la manipulación embrionaria, da origen a la permisividad que posteriormente diferentes países adoptaron para proporcionar un pie jurídico -de la norma positiva y pragmática del derecho- para sustentar las actividades de manipulación de seres humanos en fase vital inicial en condiciones de laboratorio. Sin embargo, no existe el "pre-embrión"; no existe una disciplina académica de "pre-embriología". En cambio, sí existen complejas redes de intereses utilitarios y comerciales para difundir el uso este concepto equívoco, haciendo creer que la estructura morfológica del blastocisto es un puñado de células carente de condición humana.

Con perspectiva racional-documental, y haciendo una sólida referencia al estado del arte de los conocimientos objetivos de la embriología humana, importantes autores han desentrañado meticulosamente las incoherencias y errores conceptuales en que incurren los sistemas normativos que otorgan permisividad al uso de las tecnologías de manipulación de gametos y embriones humanos, basados principalmente en los derivados del citado "Warnock report" (4-5). 
En la literatura médica colombiana es destacable el trabajo de reflexión del profesor Ramón Córdoba Palacio sobre el hecho de la "Autonomía teleológica" o estatuto antropológico del embrión humano, realidad obvia desde el inicio de su trayectoria cronológica y existencial como cigoto (6). De la copiosa obra de este médico y humanista, el artículo constituye uno de los productos más originales y significativos, recordando el hecho embrionario documentado por la gran tradición académica de los conocimientos de la morfología y embriología humanas: el desarrollo embrionario-fetal es un continuum, un proceso sin hiatos ni rupturas, caracterizado por la progresión cronológica, la continuidad, la gradualidad y la coordinación de las diferentes fases del desarrollo del ser, de las estructuras anatómicas y de sus procesos de maduración fisiológica, en su forma, en sus dimensiones y en sus niveles de diferenciación y funcionamiento. En igual sentido se han pronunciado múltiples autoridades académicas desde diversos campos del conocimiento. Merece aquí citarse como ejemplo adicional, el importante y didáctico trabajo de la autora Natalia López Moratalla (7).

La supuestamente justa permisividad en el uso de gametos y embriones ha sido un factor facilitador para la expansión del fenómeno comercial de la diseminación de instituciones dedicadas a la prestación de estos servicios. En los Estados Unidos por ejemplo, hay un crecimiento exponencial de centros dedicados a esta actividad. En otros países se ha llegado incluso a acuñar el concepto de "paraíso reproductivo", considerando las facilidades y la liberalización de normas sobre uso de gametos, embriones, uso de madres de alquiler, servicios de reproducción para mujeres solas, parejas de homosexuales, combinaciones de diferentes solicitudes, crio-preservación de gametos masculinos y femeninos, embriones congelados, hijos de diseño para obtener grupos celulares para eventuales usos terapéuticos, las diferentes técnicas de manipulación de gametos y cigotos, la inyección intra-citoplasmática, o la moda del servicio de crio-preservación de células madre provenientes de cordón umbilical o de otras fuentes.

Con facilidad, el lector puede tener un panorama de las diversas e ingeniosas estrategias de mercadeo y comercialización que incluyen alianzas comerciales, comunicación e intercambio entre diversas sedes, atractivas páginas web con contenidos "educativos" de promoción de 
servicios. En ese sentido, las tecnologías de reproducción asistida, como en algunos campos de la práctica médico-quirúrgica, se han convertido en un capítulo más de la "medicina de los deseos", en la cual el hijo se ha reducido a ser, en algunos casos, el producto final de un elaborado proceso de mercadeo, creación de necesidades y satisfacción de estas por medio de la aplicación descarnada de tecnologías que se convierten en dispensarios de un nuevo bien material disponible en el mundo del comercio: vidas humanas.

\section{Tras las cifras técnicas: la negación de lo humano}

La lectura de un documento originado periódicamente en el CDC -Center for Disease Control and Prevention- desde hace varios años, fuente de la mayor credibilidad en asuntos de estadística médica y sanitaria de los EEUU, permite adquirir una idea sobre la magnitud de lo que sucede. Desde Octubre de 2015 está disponible en la web el "2013 National Summary Report" sobre las Tecnologías de Reproducción Asistida. Este reporte contiene la información disponible proveniente de las 467 instituciones y clínicas activas en esa fecha en dicho país (8).

En el citado informe hay algunos datos que merecen ser destacados, haciendo la salvedad de que para el lector no especializado llegar a conclusiones estadísticas sólidas constituye una tarea de gran dificultad debido al modo como son presentadas las cifras. En medio de abundantes gráficos y tablas, los datos sobre el uso de embriones humanos son atenuados por una serie casi interminable de clasificaciones que ocultan las cifras más crudas, a los que es necesario llegar por análisis secundario. Ejemplo de ello es la confusión del término "ciclos" con las cifras de éxito, dadas en tablas de diferentes edades de las pacientes involucradas, pero sin consolidados que expresen con claridad el número de embriones perdidos finalmente en cada proceso de transferencia.

Se destacan unas cifras básicas: en este "2013 National Summary Report" del CDC, disponible desde Octubre de 2015. Contiene la información consolidada de las 467 clínicas dedicadas a las aplicaciones de las Tecnologías de Reproducción Asistida en humanos como se señaló; para el 
periodo reportado, se habla de un total de 190.773 ciclos, 54.323 partos y un total de 67.996 recién nacidos vivos. El porcentaje de ciclos con recién nacidos vivos a término es del $23 \%$ en menores de 35 años y del $1.2 \%$ en mujeres mayores de 44. Es bien conocida a lo largo del tiempo la correlación negativa de los porcentajes de "éxito" de estas actividades con la edad de la mujer involucrada. El porcentaje de ciclos con recién nacidos vivos en menores de 35 es 33\% y en mayores de 44 solo del $2.5 \%$. En los Estados Unidos el número total de nacimientos del año 2013 (9) es de 3.957.577; haciendo la proporción podría afirmarse que para tal periodo, el número de niños nacidos por Tecnologías de reproducción asistida alcanza el $1.7 \%$ del total de casi cuatro millones de nacimientos anuales en ese país.

Hay observaciones pertinentes adicionales sobre la manera como las cifras son presentadas en el reporte. Se confunden tasas de éxitos con los diferentes modos de cuantificarlas, no hay explícitamente referencia al número total de embriones perdidos en los procesos; también se hace énfasis en el número de ciclos, se diluyen los consolidados en las exhaustivas tablas discriminadas por edad y por otras variables - uso de embriones frescos versus el uso de embriones crio-preservados, uso de embriones propios u obtenidos por donación, en diversos grupos de edades-. Se plantean las tasas de éxitos en diferentes categorías, como por ejemplo: porcentaje de ciclos que resultan en embarazo, porcentaje de transferencias que resultan en embarazo, porcentaje de ciclos que resultan en nacimiento de recién nacido vivo -discriminados en diferentes grupos de edad de las mujeres-, porcentaje de transferencias que resultan en recién nacido vivo, y porcentaje de transferencias que resultan en recién nacido único.

Bajo esta manera de presentar las cifras, el número de datos y sus variables, se asemeja a las infinitas ramas de árboles que impiden ver las dimensiones verdaderas del bosque. ¿No es este un caso de uso deliberado de las cifras para ocultar selectivamente uno de los datos más cruciales que es precisamente, el del número total de embriones perdidos en la totalidad de los procesos evaluados?

Es una constante propia de la curva de aprendizaje de estas tecnologías que cada vez son más frecuentes las aplicaciones de ciclos con números bajos de embriones -menos de 3-, pero aun así, se continúa ocultando 
el alto número de embriones que son perdidos por diversas causas en los procesos. En una observación anterior ya citada hemos llamado también la atención sobre la realidad eugenésica de la eliminación selectiva de los embriones mediante el uso de los criterios del "Consenso de Estambul" para su valoración morfológica, discriminándolos en tres niveles diferentes de calidad, lo que representa una práctica común (2). Aún faltan más documentos sobre igual proceder en el sentido de la discriminación genética sistemáticamente usada mediante la selección de sexo del blastocisto o mediante la aplicación de tecnología de diagnóstico genético pre-implantatorio con biopsias de blastómeras, propias del uso rutinario de las tecnologías de reproducción asistida.

Sobre la etiología de la infertilidad, cabe anotar algunos datos provenientes de los "Clinical Summary Reports" -SART, para el año 2013- en los Estados Unidos (10). Brevemente se puede afirmar esto: aproximadamente en el $99 \%$ de los casos las tecnologías se refieren a FIVET -fertilización in vitro y transferencia embrionaria- y en 174.962 ciclos para ese año según este informe, las indicaciones estuvieron relacionadas con lo siguiente: baja reserva ovárica $18 \%$, factores masculino y femenino $17 \%$, factores masculinos $16 \%$, factor desconocido $13 \%$, múltiples factores femeninos $12 \%$, disfunción ovárica $7 \%$, otros $7 \%$, factor tubárico $6 \%$, endometriosis $3 \%$ y factor uterino $1 \%$. Como es sabido, en el mismo reporte se reafirma el hecho de que a mayor edad menor "éxito", es decir, menores porcentajes de ciclos con embarazo, de ciclos con recién nacido vivo, menores porcentajes de implantación y mayor número de embriones transferidos sin éxito.

Merecen una lectura crítica las importantes observaciones de autores españoles que han tratado de desentrañar el significado equívoco de la presentación de estadísticas respecto al "éxito" en las diferentes clínicas dedicadas a esta actividad. Considerando la dificultad de la interpretación de los datos presentados en el continente europeo, también allí se da la realidad de un número muy elevado de embriones que perecen en alguna fase de los procesos técnicos de fertilización in vitro y transferencia embrionaria por cada recién nacido vivo obtenido. El investigador español Justo Aznar en un juicioso y documentado análisis de cifras de diversos países, basado en reportes de la Sociedad Europea de Reproducción 
Humana y Embriología -SERHE- llega estimar estas cifras: se pierden, mueren, en los procesos de fertilización in vitro entre 7 y 13 embriones por cada recién nacido vivo. El número de embriones perdidos por cada 100 embriones producidos puede llegar a 85 . Se puede así estimar, desde el inicio del uso de estas tecnologías en 1978, que se ha causado la muerte de hasta tres decenas de millones de embriones humanos, estimando la información de la citada sociedad europea (11).

\section{Otros hechos}

Existe una creciente literatura bioética en la que se expresan reservas al uso de las Tecnologías de Reproducción Asistida en humanos, especialmente por la sentida necesidad de que los procesos de intervención sobre los aspectos reproductivos se basen en el debido respeto a la dignidad de la persona humana, sin que se atropelle el derecho fundamental a la vida tal como está sucediendo en las manipulaciones embrionarias a que se ha hecho referencia. Por supuesto, un enfoque antropológico cabal debe incluir también la aproximación humana respetuosa del sentido teleológico de la unión matrimonial y sus fines. Esto trasciende la plana concepción de un cientificismo tecnocrático que pretende confundir el "poder hacer" con el "deber hacer", evadiendo el enfoque racional del significado de la alteración de los fines de la práctica de la medicina cuando esta se convierte en dinámica de explotación económica de supuestas necesidades o de deseos y pasa a convertirse en una actividad sistemática de eugenesia y de muerte selectiva de seres humanos en el inicio de su existencia, momento que se ha convertido en uno de los de mayor vulnerabilidad para la vida desde que se dio inicio a estas prácticas de modo masivo en los años ochenta del pasado siglo ${ }^{1}$.

1 Se escapa a los objetivos de este artículo la mención a los complejísimos problemas biojurídicos derivados de la aplicación de las TRA en humanos en lo que atañe a aspectos como filiación, maternidad, paternidad, bancos de gametos y embriones, responsabilidad civil, consentimiento informado e idóneo, y a otras implicaciones contractuales del accionar técnico en estas materias. 
Es posible la investigación y práctica clínica en las que se evita la instrumentalización y degradación del ser humano -el embrión humano como "cosa" o como "producto" del poder hacer de la tecno-ciencia-. En este sentido tiene gran valor para el estudioso la consulta de autores como Gamboa, G. o del grupo de Arraztoa y col. (12-13). En estas recientes referencias bibliográficas se toca el esperanzador tema de la aplicación de la "Naprotectnología", el llamado modelo Creighton de reconocimiento de periodos de fertilidad, con el objetivo de lograr una optimización de los procesos fisiológicos normales de la fecundación e implantación. Con esta metodología se han obtenido tasas globales de embarazo del $25 \%$. Es un enfoque clínico de gran importancia, especialmente teniendo en cuenta la consideración de que un porcentaje muy importante de las causas de la infertilidad se relaciona con trastornos de la ovulación, los cuales tienen un relativo buen desenlace cuando son diagnosticados y tratados de acuerdo a este modelo incruento.

Es notable entonces, que al realizar el ejercicio de búsquedas en internet acudiendo a herramientas y sistemas de rastreo usuales en la red, quien consulta es dirigido con facilidad a páginas y recopilaciones de información básica y datos estadísticos que no ocultan la intencionalidad propagandística o comercial que los inspira.

\section{La reafirmación de lo evidente}

Las anteriores consideraciones pretenden ser una invitación al lector para aproximarse de modo crítico y prudencial a la lectura de las fuentes de información en estos tópicos y a la vez, son una invitación a la contemplación de la verdad como una misión que es propia de la disciplina de la bioética. Con ello se destaca también la necesidad de un llamado de atención hacia el juicio ponderado y racional sobre la no neutralidad ética de las aplicaciones de la tecno-ciencia.

Existe un peligro latente en esta disciplina, acertadamente señalado por el autor Francis Fukuyama. El silencio selectivo -de determinados bioeticistas- sobre el problema de los embriones desechados ocurre 
porque en algunos casos se han convertido en agentes al servicio del uso comercial de estas tecnologías bajo diferentes argumentos y en ocasiones sofismas, principalmente relacionados con los que se impusieron con el equívoco concepto de la "masa de células" de la comisión Warnock en los años 80, en evidente sometimiento de unos académicos a la necesidad que entonces tenía una institución burocrática, la HFA, de dar pronta luz verde a la licitud jurídica de una actividad comercial que ya iniciaba una carrera con gran ímpetu. Podría afirmarse que hace parte de la misma dinámica de manipulación la posterior concesión de un premio Nobel en el año 2010 por parte de la academia sueca a uno de los pioneros de las tecnologías de reproducción asistida en humanos (14).

Al respecto, Fukuyama reflexiona de esta manera:

La comunidad de bioéticos que ha surgido paralelamente a la industria biotecnológica es, en muchos aspectos, un arma de doble filo. Por un lado, ha cumplido una función extremadamente útil al plantear dudas y cuestiones sobre la prudencia y la moralidad de ciertas innovaciones tecnológicas. Por otro, muchos bioéticos se han convertido en poco más que justificadores sofisticados (y sofistas) de todo cuanto la comunidad científica desee hacer, con conocimiento suficiente de teología católica y de metafísica kantiana para rebatir los argumentos de cualquiera que, partiendo de esas tradiciones, mantenga una posición más enérgica.

(Este fenómeno es habitual y se conoce como "captura" institucional. El grupo que supuestamente supervisa las actividades de una industria se convierte en agente de ésta. Sucede por muchos motivos, incluida la dependencia que los reguladores tienen de los regulados en materia de dinero e información. Por añadidura, están los incentivos profesionales que afronta la mayoría de los bioéticos. Los científicos, de ordinario, no tienen que preocuparse por ganarse el respeto de los bioéticos, en particular si son premios Nobel de fisiología o biología molecular. Los éticos, en cambio, libran una difícil lucha por ganarse el respeto de los científicos con los que deben tratar, y no es probable que lo consigan planteándoles reparos morales o desvinculándose en exceso de la visión materialista del mundo que los científicos tanto aprecian) (15).

Existen comités y expertos de diversas disciplinas cuyos conceptos avalan y están al servicio de los intereses de quienes han hecho de las aplicaciones 
de TRA en humanos una actividad de capital importancia, incluyendo en esta importancia la magnitud de las cifras económicas involucradas con la marcha de esta industria. Dos buenos ejemplos de ello -coherentes con la citada crítica de Fukuyama- son representados por hechos como las "opiniones clínicas" del Comité de Ética de la Sociedad Americana de Medicina Reproductiva en su concepto sobre los embriones abandonados luego de un determinado periodo y la Opinión Clínica del equivalente comité del Colegio Americano de Ginecología y Obstetricia (ACOG) y el de la Federación Internacional de Ginecología y Obstetricia, (FIGO) sobre el uso de embriones pre-implantatorios para investigación (16-17).

Además, son interesantes las consideraciones elásticas de aquellas instituciones en cuanto a definiciones fundamentales francamente equívocas y contrarias a la verdad, como la definición de la FIGO del término "embarazo" como un "proceso que se inicia luego de la implantación del blastocisto", negando la realidad conocida de los acontecimientos morfológicos y fisiológicos de los primeros días desde el "momento cero" del inicio del proceso de la fusión de los gametos, formación del cigoto humano e inicio del proceso de clivaje, formación de blastómeras e inicio de diferenciación celular. En contradicción con los hechos, aquellas instituciones y expertos promueven definiciones y conceptos que pretenden dar como un hecho comprobado que lo humano carece de realidad ontológica en las fases iniciales del desarrollo embrionario.

\section{Una glosa sobre el consentimiento informado $y$ consideraciones finales}

El acto humano libre debe incluir el cabal hecho de la comprensión racional de lo que se hace; así podría hablarse de responsabilidad ética en la acción. Vale la pena aquí formularse un cuestionamiento ya insinuado con anterioridad por algunos autores: si la pareja que se somete a estas tecnologías en condición de usuario -el cliente desconoce el real número de los embriones que son producidos por la aplicación de las técnicas y luego desechados, sus propios hijos concebidos in vitro-, cies válido su consentimiento? ¿Se les ha presentado, por parte de los tecnócratas 
interesados en la aplicación y difusión de las técnicas con el fin de satisfacer a toda costa las solicitudes de sus clientes, la realidad numérica de estas pérdidas embrionarias? ¿Se les ha hecho la clara observación acerca del sentido antropológico del acto de crio-preservar y luego eliminar deliberadamente seres humanos en un proceso que en realidad no es terapéutico? ¿Se les ha explicado que estas técnicas no son terapéuticas?

El ocultamiento selectivo de estas realidades antropológicas -o de partes de sus significados- invalidaría los consentimientos solicitados y firmados para los efectos jurídicos implicados. Este es quizás un buen camino adicional de reflexión para la disciplina de la bio-jurídica, ya explorado afortunadamente por diversos autores que desde esta perspectiva han hecho conocer sus valiosas observaciones y cuestionamientos. No sobra destacar en este momento la también evidente situación de colisión de intereses a partir de la cual la presentación de los datos hacia los usuariosclientes es precisamente orientada y sesgada por parte de los propios interesados en la difusión comercial de su actividad, enfoque comercial que a la vez es mimetizado bajo el manto de avance científico y de "servicio" de carácter médico.

Los embriones humanos sobrantes, producto de la aplicación extensiva de las TRA pueden equipararse a una nueva clase de inmigrantes, náufragos confinados a una tecnocrática versión de la tragedia de los infortunados ocupantes de la balsa de La Medusa. Su destino casi seguro es la muerte, una muerte "in vitro", generalmente en fase de embrión pre-implantatorio. Este es un proceso de muertes de seres humanos consentida por unos padres que contratan aquellos servicios, animados por diversas razones pero muy posiblemente desconocedores de detalles estadísticos en cuanto al alto número de pérdidas de sus propios hijos en los procesos.

Estas acciones son ejecutadas por técnicos de laboratorio que constituyen el motor efectivo de operación de la inicua industria de la reducción del embrión humano a la condición de cosa. No existe allí "terapia" en el sentido estricto del concepto. No hay curación de la infertilidad. Sí tiene lugar la provisión comercial de seres humanos por solicitud y contrato, producto del deseo de quienes lo solicitan y de los intereses y fuerzas del 
mercado a que responden quienes proveen los servicios. Una combinación de poder de la tecno-ciencia con habilidosas formas de mercadeo: esto constituye un doloroso episodio adicional del ocultamiento del horizonte de lo humano que bien merecería una mayor consideración y revisión desde diversos ámbitos: social, medios de comunicación, vida académica, vida jurídica, bioética. Aquí también puede constatarse que bajo el disfraz del progreso se ha deformado de modo sutil el fin de la medicina -proteger, cuidar, promover la dignidad de la vida de todo ser humano, sin discriminación- y se ha retrocedido a formas no tan lejanas en la historia del siglo XX de prevalencia de una sistemática mentalidad eugenésica y utilitarista que se niega a aceptar una parte de la realidad que puede parecer incómoda e inoportuna: los embriones muertos durante estas aplicaciones son seres vivos que hacen parte de la especie humana.

Con estas ideas se ha pretendido aportar a la formación de una conciencia crítica mediante la cual el discernimiento racional ordenado se atreva a cuestionar y señalar los graves problemas bioéticos -racionales y antropológicos- que aún quedan sin resolver en esta materia. No todo lo que se puede hacer técnicamente es lícito. De modo equivalente, no todo lo que las normatividades legales actuales han dado como válido es coherente con una visión ética que defiende y afirma el valor de la dignidad, cualidad intrínseca de todo ser humano que merece ser respetado en uno de sus valores fundantes: el valor de la propia existencia del ser humano.

\section{Lista de referencias}

ACOG Committee Opinion. "Using pre-implantation embryos for research". 347. (2006). < https://www.ncbi.nlm.nih.gov/ pubmed/17077265>.

Álvarez Díaz, Jorge Alberto. "Historia contemporánea: las técnicas complejas de reproducción asistida". Ginecología y Obstetricia de México 75 (2007): 293-302.

Aznar, Justo. "La fertilización in vitro: más muerte que vida". Pontifical Academy for Life. 18 General Assembly (Member Communications) 
Rome, 23-25 Febr 2012.

Arraztoa, J.A. y col. "Experiencia preliminar en el uso de registros de fertilidad en una cohorte de pacientes con infertilidad en un servicio de ginecología y obstetrician". Medicina UPB 34.1. (2015): 9-15.

Center for Disease Control and Prevention. Oct. $20015<$ http://www.cdc. gov/art/reports/>.

. 13 marzo. 2016 <http://www.cdc.gov/art/pdf/2013-report/ art_2013national_summary_report.pdf $>$.

Córdoba Palacio, Ramón. "La autonomía teleológica y el estatuto antropológico del embrión humano". Revista Selecciones de Bioética (Cenalbe). 5 (2004): 36-44.

Ethics Committee of the American Society of Reproductive Medicine. "Disposition of abandoned embryos: a committee opinion". Fertil Steril 99.7. (2013): 1848-1849.

$<$ https://www.asrm.org/uploadedFiles/ASRM_Content/News_and Publications/Ethics_Committee_Reports_and_Statements/ abandonedembryos.pdf $>$.

Fukuyama, Francis. El fin del hombre. Consecuencias de la revolución biotecnológica. Barcelona: Ediciones B, 2002.

Gamboa, G. "Investigación en fertilidad: una perspectiva bioética". Medicina UPB. 34.1. (2015): 40-48.

Gómez Fajardo, Carlos A. "Observaciones bioéticas sobre el Consenso de Estambul: el cientificismo y la omisión de lo humano en la embriología humana". Revista Persona y Bioética 18.1. (2014): 35-45.

Herranz, Gonzalo. El embrión ficticio. Historia de un mito biológico. España: Ediciones Palabra, 2013.

López Moratalla, Natalia. "La realidad del embrión humano en los primeros quince días de vida”. Persona y bioética 8.21 (2004): 6-23.

L. Vivanco, Bartolome B, Martínez A. "Tendencia del uso del término preembrión en la literatura científica. Análisis comparado entre 1999 y 2008". Cuadernos de Bioética 20.3 (2009): 554.

National Vital Statistics Reports vol. 63 N. 2. 29. May. 2014 <https:// www.cdc.gov/nchs/data/nvsr/nvsr63/nvsr63_02.pdf>. 
Nobelprize.org. 13 Marzo. 2016 <www.nobelprize.org/nobel_prizes/ medicine/laureates/2010/edwards-facts.htlm>.

Ortega y Gasset, José. La rebelión de las masas. Madrid: Espasa, 2006. 